\title{
Revascularisation in diabetic "small vessel disease" of lower limbs: is it worthwhile?
}

\author{
S M Wijeyaratne ${ }^{1}$
}

(Index words: Limb salvage, preventing major amputation, independent mobility)

\begin{abstract}
Background Diabetic patients with critical ischaemia of the lower limb despite a palpable popliteal pulse are presumed to have 'small vessel disease' that is unreconstructable and often subjected to major amputation. Results of revascularisation in such patients are presented.

Methods A prospective observational study of revascularisation [ $n=23,14$ men, mean age 62 years (range 47 to 80 )] using saphenous vein to bypass occluded infrapopliteal arteries in diabetics with critical leg ischaemia over a 5-year period.
\end{abstract}

Outcome measures Surgical mortality, graft patency, major amputation rate, time taken for healing, ambulation after discharge from hospital.

Results There was one death within 30 days of surgery. $2 / 4$ early thromboses were salvaged, $5(5 / 22)$ limbs were amputated. Limb salvage was $17 / 23(74 \%)$. Two limbs were amputated because of thrombosis and 3 were amputated for spreading sepsis despite a patent graft. 2 late graft failures were detected but the limbs remain healed and functional. $15 / 23(65 \%)$ re-vascularisations remained patent at a mean follow up of 30 months (range 4 to 60 ). Mean wound healing time was 30 days (range 16 to 45 ). 14/17 (82\%) of those with salvaged limbs were independent with regard to ambulation.

Conclusion Bypass of diabetic small vessel disease of the lower limbs is feasible and effective in preventing major amputation and maintaining independent mobility.

\section{Introduction}

Diabetes mellitus has reached epidemic proportions in south Asia (1) and diabetic foot complications are the commonest cause of non-traumatic lower limb amputation (2). Ischaemia plays a central role in loss of limbs which are predisposed to injury from diabetic neuropathy. Correction of ischaemia by revascularisation is crucial if these limbs are to be saved. The unfortunate dictum of present medical teaching that the distal limb of diabetic patients is plagued by occlusive 'small vessel disease' (3) is probably responsible for the negative approach to revascularising the diabetic ischaemic limb. This idea originated over 40 years ago from a retrospective histological study on arterioles in amputation specimens from patients with diabetes (4). However, the presence of such occlusive microvascular disease has not been substantiated since $(5,6,7)$. In fact, a recent report using laser Doppler flowmetry (8) and high-resolution television microscopy has shown an increase in the capillary blood flow in diabetics (9).

A patent diabetic microvasculature is the basis for revascularisation by very distal bypass procedures, even going as far down as the foot vessels. Nevertheless, surgery on such tiny diseased vessels is more liable to fail without saving limbs. Furthermore, co-morbidities in this group may prevent independent walking even after limb salvage. In recent years there have been a few reports from the west on bypass grafts to the feet to accomplish limb salvage (10-14). There are no such reports from Asia in the indexed literature and the purpose of this study was to assess the feasibility, safety, effectiveness and value of revascularisation to save diabetic lower limbs in Sri Lanka.

\section{Methods}

Over a 5-year period, 23 diabetic patients [ 14 men and 9 women, mean age of 62 years (range 47 to 80)] underwent primary distal bypass procedures. All patients had critical ischaemia manifested by various combinations of gangrene, non-healing minor amputation wounds and pressure ulceration with absent ankle pulses despite a palpable popliteal pulse (Table 1). All were type 2 diabetics for an average period of 13 years (range 8 to 16 ) and needed soluble insulin during the perioperative period.

\section{Table 1. Presentation of critical ischaemia}

Gangrene of toes 4

Non-healing amputations

Non-healing transmetatarsal amputations 2

Heel ulceration and gangrene over bony pressure points, interdigital areas under tight bandages

Their median ankle brachial Doppler index was 0.40 (iqr 0.2 to 0.8 ). All had varying degrees of pain interfering with sleep and requiring strong analgesics. Two had already lost one limb from diabetic complications. 
18 of the 23 selected for revascularisation underwent conventional contrast arteriography pre-operatively. The presence of a satisfactory popliteal artery with occlusion confined to distal popliteal, tibial and peroneal vessels was confirmed (Figure). The outflow vessel was evident in 6 (33\%). Additionally, 18 consecutive patients underwent colour duplex ultrasound assessment of the vascular tree before arteriography. Five patients underwent bypass surgery without an arteriogram due to non-availability of the facility from machine breakdown, long delays in obtaining arteriograms or contraindications to imaging contrast. Duplex ultrasonography and surgical exploration of paramalleolar vessels determined the optflow adequacy and operability in these patients.

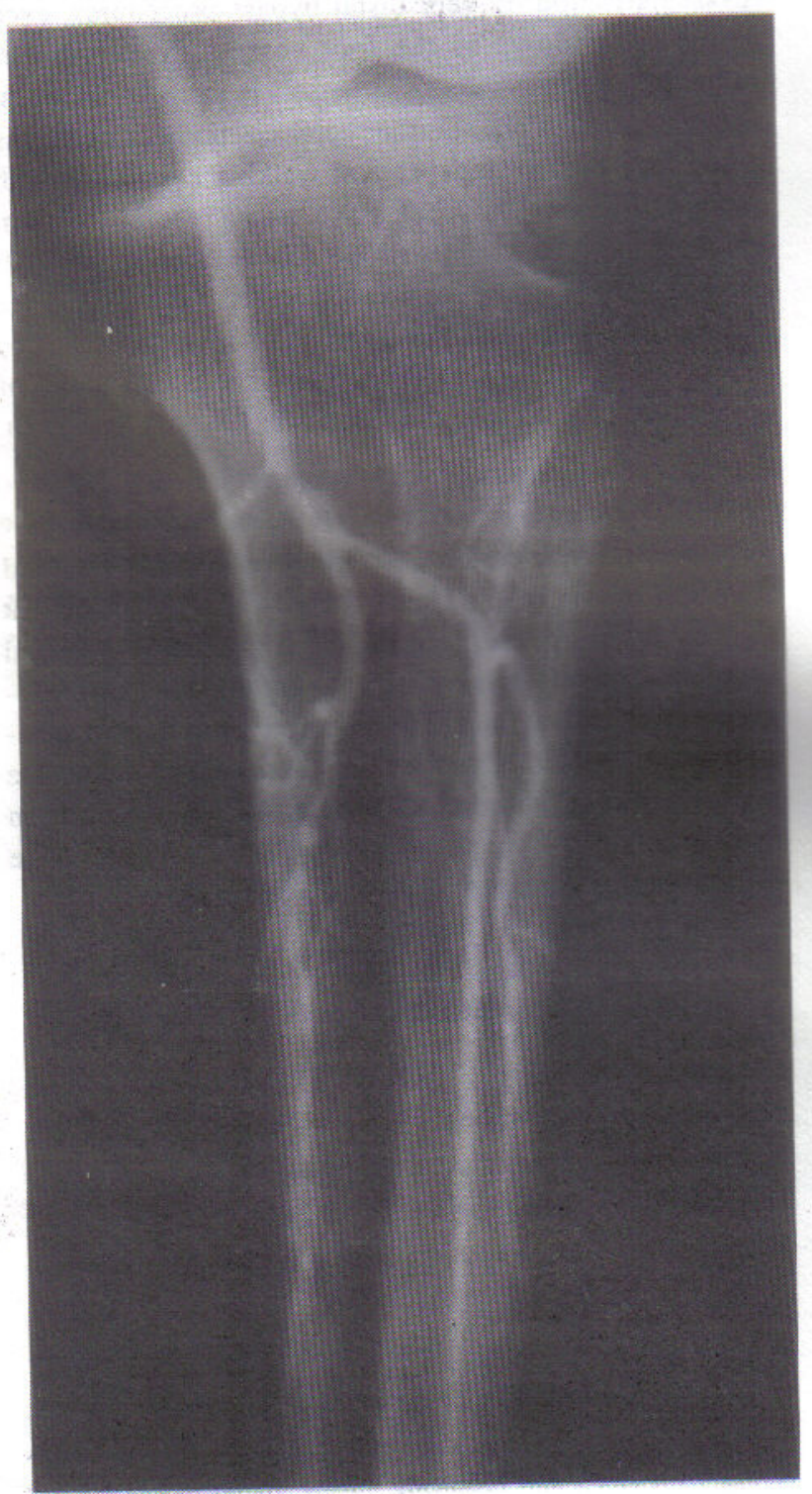

Figure. Arteriogram demonstrating characteristic 'diabetic tibial disease'. The proximal popliteal is spared, while long segments of tibial vessels are involved.
The proximal anastomosis (inflow) was from the infragenicular popliteal artery in 22 and the distal anterior tibial artery in one. The outflow vessels were the anterior tibial, posterior tibial, dorsalis pedis and common plantar arteries (Table 2). 10 patients underwent reconstruction using the in situ long saphenous vein as described previously (18). The remaining 13 underwent reconstruction using reversed long saphenous vein taken from above the knee. All patients were anticoagulated for three months. Graft patency was monitored by palpation and duplex ultrasound.

Table 2. Distribution of sites of proximal and distal anastomoses

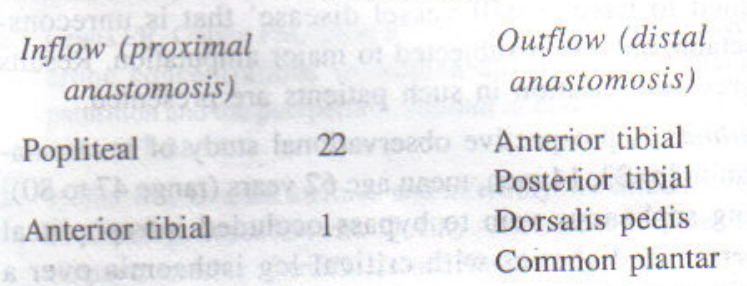
4

\section{Results}

There was one death within 30 days of surgery (4.3\%). $5(5 / 22)$ limbs were amputated, 2 due to thrombosis and 3 due spreading sepsis despite a patent graft. Four grafts thrombosed early (within 30 days), but two were salvaged by thrombectomy. 2 late graft failures were detected but the limbs remained healed and functional. With respect to the 4 grafts that thrombosed 2 were in situ vein grafts and the others were reversed veins.

15 revascularisations remained patent at a mean follow up of 30 months (range 4 to 60 months). Limb salvage was 17 of $23(74 \%)$. Graft patency was 15 out of $23(65 \%) .14 / 17$ $(82 \%)$ of those with salvaged limbs were ambulant and independent. Two of them had undergone previous major amputations.

\section{Discussion}

All patients in this series had critical ischaemia manifesting as gangrene of toes, non-healing minor amputation wounds or ulceration, and faced the prospect of imminent amputation. The chronicle of the diabetic patient undergoing amputation of first a toe, then the forefoot (transmetatarsal) and later at the above or below-knee level is known to many. This is unfortunately so because of the widespread idea that diabetics have occlusive 'small vessel disease'. Results from an aggressive approach to revascularisation presented in this paper do not support this and are in keeping with the findings of other studies that have demonstrated a patent pedal vasculature in most diabetics.

Haimovici (16) was the first to compare the arteriographic pattern of atheroma in diabetics and in nondiabetics. Occlusion of the distal popliteal and two or all three leg vessels (diabetic tibial disease) was twice as frequent in diabetics. In addition, occlusion and disease of 
18 of the 23 selected for revascularisation underwent conventional contrast arteriography pre-operatively. The presence of a satisfactory popliteal artery with occlusion confined to distal popliteal, tibial and peroneal vessels was confirmed (Figure). The outflow vessel was evident in 6 (33\%). Additionally, 18 consecutive patients underwent colour duplex ultrasound assessment of the vascular tree before arteriography. Five patients underwent bypass surgery without an arteriogram due to non-availability of the facility from machine breakdown, long delays in obtaining arteriograms or contraindications to imaging contrast. Duplex ultrasonography and surgical exploration of paramalleolar vessels determined the optflow adequacy and operability in these patients.

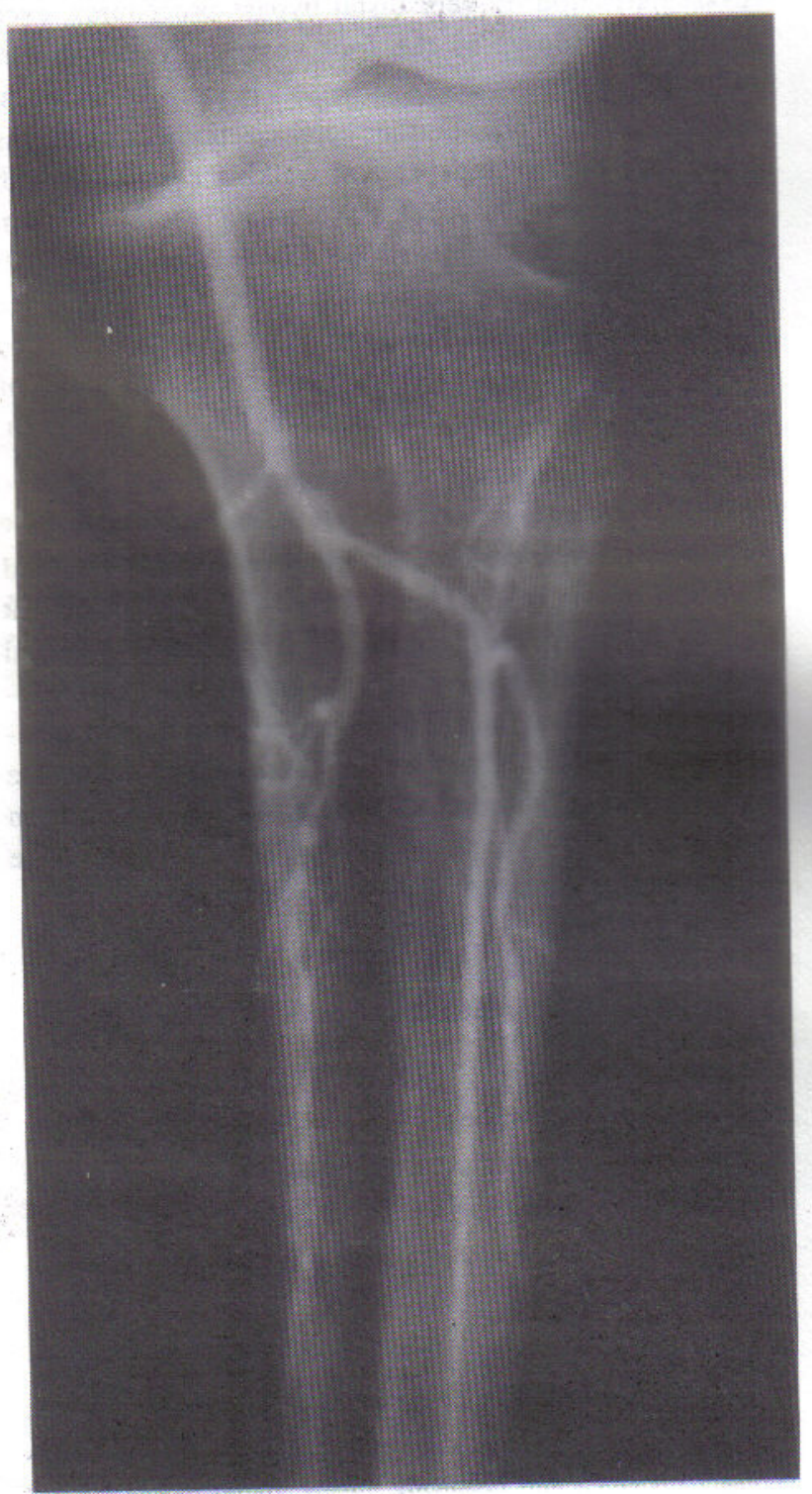

Figure. Arteriogram demonstrating characteristic 'diabetic tibial disease'. The proximal popliteal is spared, while long segments of tibial vessels are involved.
The proximal anastomosis (inflow) was from the infragenicular popliteal artery in 22 and the distal anterior tibial artery in one. The outflow vessels were the anterior tibial, posterior tibial, dorsalis pedis and common plantar arteries (Table 2). 10 patients underwent reconstruction using the in situ long saphenous vein as described previously (18). The remaining 13 underwent reconstruction using reversed long saphenous vein taken from above the knee. All patients were anticoagulated for three months. Graft patency was monitored by palpation and duplex ultrasound.

Table 2. Distribution of sites of proximal and distal anastomoses

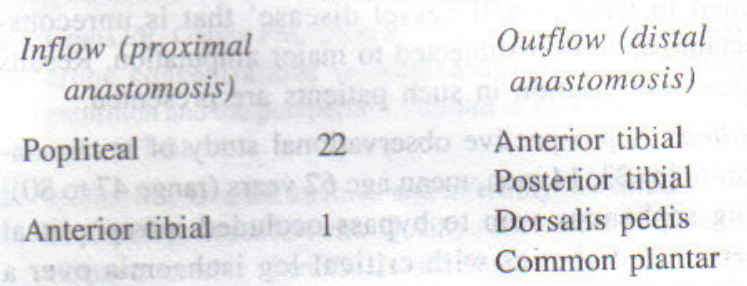
4

\section{Results}

There was one death within 30 days of surgery (4.3\%). $5(5 / 22)$ limbs were amputated, 2 due to thrombosis and 3 due spreading sepsis despite a patent graft. Four grafts thrombosed early (within 30 days), but two were salvaged by thrombectomy. 2 late graft failures were detected but the limbs remained healed and functional. With respect to the 4 grafts that thrombosed 2 were in situ vein grafts and the others were reversed veins.

15 revascularisations remained patent at a mean follow up of 30 months (range 4 to 60 months). Limb salvage was 17 of $23(74 \%)$. Graft patency was 15 out of $23(65 \%) .14 / 17$ $(82 \%)$ of those with salvaged limbs were ambulant and independent. Two of them had undergone previous major amputations.

\section{Discussion}

All patients in this series had critical ischaemia manifesting as gangrene of toes, non-healing minor amputation wounds or ulceration, and faced the prospect of imminent amputation. The chronicle of the diabetic patient undergoing amputation of first a toe, then the forefoot (transmetatarsal) and later at the above or below-knee level is known to many. This is unfortunately so because of the widespread idea that diabetics have occlusive 'small vessel disease'. Results from an aggressive approach to revascularisation presented in this paper do not support this and are in keeping with the findings of other studies that have demonstrated a patent pedal vasculature in most diabetics.

Haimovici (16) was the first to compare the arteriographic pattern of atheroma in diabetics and in nondiabetics. Occlusion of the distal popliteal and two or all three leg vessels (diabetic tibial disease) was twice as frequent in diabetics. In addition, occlusion and disease of 
the tibial vessels generally involved long segments of vessel in diabetics, as illustrated in the figure rather than being patchy in distribution as was observed in the limbs of non-diabetic patients. Although contrast arteriography is often considered the technique of choice for providing the best anatomical picture of the site for distal anastomosis, this was not the case in my series, with only $33 \%$ of the pictures showing a distal vessel. More recently Doppler insonation $(17,18)$, pulse generated run-off $(18)$ and duplex ultrasonography have been shown to be invaluable in determining which distal vessel is patent. Indeed, in 17/23 studied, the run-off vessel for distal revascularisation was selected on Duplex ultrasonography alone. Failure of arteriography is attributed to poor equipment and technique, especially the timing of pictures, and thus should not be considered the final arbiter of operability.

Outcomes of revascularisation in diabetic patients with tibial small vessel disease have proved worthwhile both in terms of vein graft patency rates and limb salvage. Additionally, the success of bypass grafting is independent of whether the segment of vein is in situ or reversed. These results are similar to those reported from the USA $(13,14)$. Nevertheless, long healing times and hospitalisation for the revascularised patients in this series was due to previous minor amputations and debridement of ischaemic tissue resulting in most patients having deep sepsis, extensive skin loss and osteomyelitis at the time of referral. Major amputations of 3 grafted limbs were also caused by such problems. Appreciation of the need for immediate revascularisation of such limbs rather than minor amputations and repeated debridement of ischaemic tissue could save many limbs.

The significant benefit of limb salvage in regard to independent ambulation is also confirmed in this study. Limited facilities for rehabilitation and difficulties in obtaining artificial limbs compounds the problems faced by the elderly diabetic lower limb amputee in Sri Lanka. The immense cost-effectiveness of salvage surgery has been established in the developed world $(19,20)$ and this would be of greater relevance to poor countries such as Sri Lanka. Prevention of amputation in the growing population of elderly diabetics assumes much greater importance in the economically deprived south Asian region.

\section{References}

1. King H, Aubert RE, Herman WH. Global burden of diabetes, 1995-2025: prevalence, numberical estimates, and projections. Diabetes Care 1998; 21: 1414-31.

2. Young MJ, Boulton AJ, Macleod AF, et al. A multicentre study of the prevalence of diabetic peripheral neuropathy in the United Kingdom hospital clinic population. Diabetologia 1993; 36: 150-62.
3. LoGerfo FW, Coffman JD. Vascular and microvascular disease of the foot in diabetes; implications for foot care. New England Journal of Medicine 1984; 311: 1615-9.

4. Goldenberg SG, Alex M, Joshi RA, Blumenthal HT. Non-atheromatous peripheral vascular disease of the lower extremity in diabetes mellitus. Diabetes 1959; 8: 261-73.

5. Strandness DE, Priest RE, Gibbons GE. Combined clinical and pathologic study of diabetic and nondiabetic peripheral arterial disease. Diabetes 1964; 13: 366-72.

6. Conrad MC. Large and small artery occlusion in diabetics and nondiabetics with severe vascular disease. Circulation 1967; 36: $83-91$

7. Barner HB, Kaiser GC; Willman VL. Blood flow in the diabetic leg. Circulation 1971; 43: 391-4.

8. Flynn MD, Edmonds ME, Tooke JE, Watkins PJ. Direct measurement of capillary blood flow in the diabetic neuropathic foot. Diabetologia 1988; 31: 652-6.

9. Irwin ST, Gilmore J, McGrann S, Hood J, Allen JA. Blood flow in diabetics with foot lesions due to 'small vessel disease'. British Journal of Surgery 1988; 75: 1201-6.

10. Ascer E, Veith FJ, Gupta SK. Bypasses to plantar arteries and other tibial branches: an extended approach. Vascular Surgery 1988; 8: 434-41.

11. Wengerter KR, Yang PM, Veith FJ, et al. A twelve-year experience with the popliteal-to-distal artery bypass: the significance and management of proximal disease, Journal of Vascular Surgery 1992; 15: 143-51.

12. Verhelst R, Bruneau M, Nicolas AL, et al. Popliteal-to-distal bypass graft for limb salvage. Annals of Vascular Surgery 1997 ; 11: $505-9$.

13. Andros G. Bypass grafts to the ankle and foot; a personal perspective. Surgical Clinics of North America 1995; 75: 715-29.

14. Pomposelli FB Jr, Marcaccio EJ, Gibbons GW, Campbell DR, Freeman DV, Burgess AM, et al. Dorsalis pedis arterial bypass: durable limb salvage for foot ischemia in patients with diabetes mellitus. Journal of Vascular Surgery 1995; 21: 375-84.

15. Rhodes GR, Rollins D, Sidawy AN, Skudder, P, Buchbinder D. Popliteal-to-tibial in situ saphenous vein bypass for limb salvage in diabetic patients. American Journal of Surgery 1987; 154: $245-7$.

16. Haimovici H. Patterns of arteriosclerotic lesions of the lower extremity. Archives of Surgery 1967; 95: 918-33.

17. Shearman CP, Gwynn BR, Curran F, Gannon MX, Simms MH. Non-invasive femoropopliteal assessment: is that angiogram really necessary? British Medical Journal 1986; 293: 1086-9.

18. Beard JD, Scott DJA, Evan JM, Skidmore R, Horrocks M. Pulse generated run off: a new method of determining calf vessel patency. British Journal of Surgery 1988; 75: 361-3.

19. Taylor LM, Hamre D, Dalman RL, Porter JM. Limb salvage vs amputation for critical ischaemia. The role of vascular surgery. Archives of Surgery 1991; 126: 1251-8.

20. Anonymous. Amputation or arterial reconstruction? Lancet 1992; 339: 900. 